\title{
To what extent have sweetened beverages contributed to the obesity epidemic?
}

\author{
Gail Woodward-Lopez*, Janice Kao and Lorrene Ritchie \\ Dr Robert C. and Veronica Atkins Center for Weight \& Health, University of California, 3 Giannini Hall \#3100, \\ 94720-3100 CA, Berkeley, USA
}

Submitted 13 January 2010: Accepted 30 June 2010: First published online 23 September 2010

\begin{abstract}
Objective: A systematic literature review was conducted to determine whether sweetened beverage intake increases the risk for obesity, and the extent to which it has contributed to recent increases in energy intake and adiposity in the USA.

Design: The search included studies published between 1970 and 2010 that examined secular trends, mechanisms, observational associations and intervention outcomes. Observational and intervention studies were abstracted and systematically evaluated for quality.

Setting: Trends in obesity prevalence in the USA and studies from industrialized (developed) countries were included.

Subjects: Studies were included for all ages, genders, ethnic and socio-economic groups for which data were available.

Results: Obesity rates and sweetened beverage intake have increased in tandem in the USA. Studies consistently show that higher intake of sweetened beverages is associated with higher energy intake. Energy in liquid form is not well compensated for by reductions in the intake of other sources of energy. Well-designed observational studies consistently show a significant positive relationship between sweetened beverage intake and adiposity. More importantly, several well-conducted randomized controlled trials have shown statistically significant changes in adiposity as a result of corresponding changes in sweetened beverage intake.

Conclusions: All lines of evidence consistently support the conclusion that the consumption of sweetened beverages has contributed to the obesity epidemic. It is estimated that sweetened beverages account for at least one-fifth of the weight gained between 1977 and 2007 in the US population. Actions that are successful in reducing sweetened beverage consumption are likely to have a measurable impact on obesity.
\end{abstract}

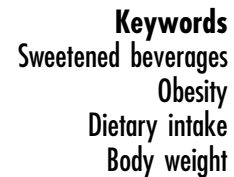

During the past 30 years, there has been a substantial increase in the prevalence of overweight and obesity $\dagger$ in both adults and children and among all ethnic and socio-economic groups in the USA. During this same 30-year period, studies of immigrant populations have found that subsequent generations of Americans tend to be heavier, pointing to the US environment as a likely contributing factor ${ }^{(1)}$.

Findings suggest that increases in energy availability and intake have played a critical role in the increased prevalence of obesity. Between the late 1970s and 2000, the amount of energy available for human consumption in the USA increased by more than $2092 \mathrm{~kJ}(500 \mathrm{kcal}) / \mathrm{d}$ per capita, even after adjusting for estimated spoilage, cooking, plate waste and other losses ${ }^{(2)}$. Data from two national surveys of food intake over the same time period

$\dagger$ Overweight in adults is defined as having BMI $\geq 25$ and $<30 \mathrm{~kg} / \mathrm{m}^{2}$; obesity in adults is defined as BMI of $\geq 30 \mathrm{~kg} / \mathrm{m}^{2}$. suggest a more modest, but nevertheless substantial, increase of nearly $1255 \mathrm{~kJ}$ (300 kcal)/d per capita (all ages combined) ${ }^{(3-5)}$.

Compared to dietary data, relatively few data are available on changes over time in physical activity levels. No single survey or data set has examined activity levels over the entire time period in the USA, and therefore data must be compared from several studies using varied methodologies that examined various shorter time periods, different subsets of the population and different types of physical activity. The limited available data suggest that there have not been substantive changes in physical activity levels in the USA in recent decades ${ }^{(6-9)}$. A recent report found that adults (aged 18-50 years) in the USA and Europe currently burn about the same amount of energy on physical activity as they did 20 years ago ${ }^{(10)}$. This meta-analysis of thirteen studies involving nearly 400 subjects included only investigations that used doubly labelled water to measure energy expenditure. 
However, subjects' activity habits or weight changes may not have been representative of the general population.

Inadequate physical activity levels during this period, however, are well documented ${ }^{(11-13)}$, and when combined with dramatic increases in energy supply, have likely left the US population susceptible to obesity. This susceptibility is due, in part, to the fact that an individual's energy homeostasis relies upon physiological signals both for hunger - which are very efficient - and for satiety which, by comparison, are relatively inefficient ${ }^{(14)}$.

The impact of energy intake on satiation and satiety varies with the characteristics of the food ${ }^{(15)}$. This suggests that obesity is not the result of just eating too much of everything, and that identifying which food choices are contributing most to the current obesity epidemic is imperative.

Neither children nor adults in the USA come close to meeting the guidelines for balanced dietary intake ${ }^{(16,17)}$. Only $1 \%$ of children meet the 1995 Dietary Guidelines with regard to core, healthful food groups ${ }^{(16)}$. Sugar in liquid form accounts for almost half the total added-sugar intake in the US population ${ }^{(18,19)}$ and sweetened beverages displace healthier and/or more nutrient-dense beverages like milk, $100 \%$ fruit juice and water ${ }^{(20-23)}$. Given the correspondence between the rapid rise in obesity and a similarly rapid increase in sweetened beverage intake by all age and ethnic groups in the USA ${ }^{(2,20,24-27)}$, sweetened beverages have been identified as a likely risk factor for obesity and a target for intervention. Of particular concern is the higher intake of sweetened beverages by those at most risk for obesity: African Americans, Mexican Americans and lower education and income populations ${ }^{(25)}$.

The present paper examines the literature regarding the relationship between sweetened beverages* and obesity and seeks to evaluate the contribution of this factor to the obesity epidemic in the USA.

\section{Methods}

A systematic search of the PubMed Database identified studies examining the association between sweetened beverages and adiposity. The following inclusion criteria were used.

- Search limits: publication dates from January 1970 to March 2010; English; human.

- Search terms: soda; soft drinks; sweetened beverages; fruit drinks, obesity, overweight, body weight.

* For the purposes of the present paper, when speaking in general terms, 'sweetened beverages' refers to any combination of beverages that contains added caloric sweetener. However, individual studies and data sets referred to in the present paper used variable definitions, most commonly as follows: 'sweetened beverages' - any beverage with added caloric sweetener, most commonly includes fruit-flavoured drinks and sodas and sometimes includes low-calorie drinks, sweetened teas and coffees; 'soft drinks or sodas' - caloric-sweetened carbonated beverages (sometimes includes diet drinks); 'fruit drinks' - non-carbonated fruitflavoured drinks with added caloric sweetener including 'ades' and punches. In many cases, no definition was provided.
Abstracts identified through the search process were reviewed by the authors and trained academic research staff. Training studies, weight loss studies and studies of populations with chronic diseases were excluded. Studies had to have been conducted in a developed country and had to fall into one of the following categories.

- Secular trends: reports on the intake of sweetened beverages in the USA, to determine the extent to which changes correspond to recent increases in the prevalence of obesity.

- Mechanisms: studies that examine mechanisms that explain the relationship between sweetened beverage intake and obesity.

- Observational studies: studies that examine the relationship between adiposity $\dagger$ and sweetened beverage intake in free-living populations.

- Intervention trials: studies that examine the impact on adiposity of programmes designed to improve health or prevent weight gain by reducing the consumption of sweetened beverages, or that study the impact on weight of prescribed increases in sweetened beverage intake.

Meta-analyses of observational studies and intervention trials relating sweetened beverage intake to adiposity were included if they estimated effect size.

Papers that met the criteria were abstracted by the authors and/or trained research staff onto a standardized form that included information on sample size and demographics, study design and methodology, sampling strategy, statistical analyses, control variables, dependent and independent variables, design/methodological strengths and weaknesses and study results.

Each published observational study was given a quality score of plus, neutral (0) or minus using the American Dietetic Association's (ADA) Quality Criteria Checklist, based on the Agency for Healthcare Research and Quality domains for research studies ${ }^{(28)}$. The checklist includes four questions about the relevance of the results to the central question of the review and ten questions about the validity of the results using information about study design, methods of data collection and analysis. The answers to the relevance and validity questions are the basis for assigning the quality scoret.

The authors then examined the proportion of studies with a given result and quality rating to determine whether the preponderance of higher-quality studies supported an association between beverage intake and adiposity. The experimental studies were not rated, but because

\footnotetext{
$\uparrow$ For the purposes of the present paper, adiposity refers to any measure of body fat, including BMI, as well as more direct measures such as skinfold measures, bioelectrical impedance (BIA) and dual-energy X-ray absorptiometry (DXA).

\$ Specific questions within the validity categories may be found at the ADA Evidence Analysis Library website (http://www.adaevidencelibrary. $\mathrm{com} /$ topic.cfm?cat $=1234$ ).
} 
they were more limited in number, their relative merits were analysed and are described in more detail. The authors' conclusions are based on both the relative number and quality of studies with a given result.

\section{Secular trends in sweetened beverage consumption}

Sweetened beverage intake and the prevalence of obesity have risen over the same time period

Although parallel trends cannot establish causation, the correspondence between the rapid rise in obesity and a simultaneous rapid increase in sweetened beverage intake and overall energy intake points to sweetened beverages as a likely contributor to the obesity epidemic in the USA $^{(2,20,24-26)}$. Between 1977 and 2002, Americans on average increased their energy intake from soft drinks by $228 \%$ and their energy intake from fruit drinks by $171 \%{ }^{(29)}$ (Fig. 1).

All ethnic and age groups, including the very young, have increased their sweetened beverage consumption $^{(20,24,25,27,29-33)}$; the percentage of total energy coming

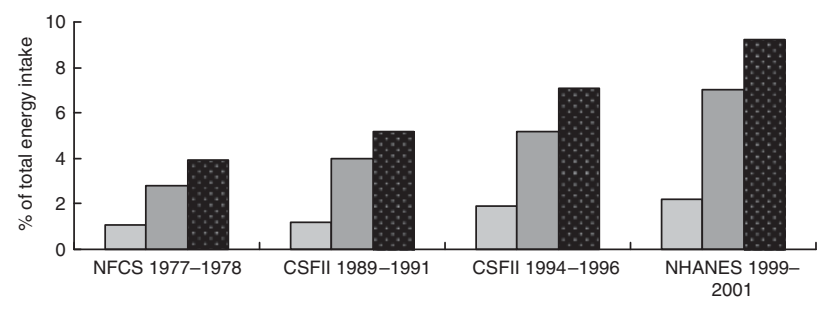

Fig. 1 Trends in US beverage consumption ( $\square$, fruit drinks; $\square$, soft drinks; sweetened beverages) as a percentage of total daily energy intake (Nationwide Food Consumption Survey, 1977-1978; Continuing Survey of Food Intakes by Individuals, 1989-1991, 1994-1996; National Health and Nutrition Examination Survey, 1999-2001) ${ }^{(24)}$ from sweetened beverages has more than doubled for all age groups (Fig. 2).

\section{Sweetened beverages contribute a substantial amount of energy to the diet of Americans}

Soft drinks contribute more energy to the diet than any other single type of food or beverage; they are also the top source of liquid energy in the USA ${ }^{(4,34,35)}$. By 1999-2004, adults (aged 20-44 years) consumed 12\% of their total daily intake from sweetened beverages, while children aged 2-18 years obtained $10 \%$ and teenagers $13 \%$ of their energy from these drinks ${ }^{(25,26)}$. Lytle et al. ${ }^{(36)}$ reported that as students moved from elementary to middle school, the proportion of beverages consumed as soft drinks more than tripled, while milk and 100\% fruit juice consumption declined substantially. Data collected between 1999 and 2004 revealed that boys aged 13-18 years consume the most sweetened beverages of all age and gender groups: an average of $1494 \mathrm{~kJ}$ $(357 \mathrm{kcal}) / \mathrm{d}^{(30)}$. Those at most risk for obesity, including African Americans, Mexican Americans and lower education and income populations, have the highest intake of sweetened beverages ${ }^{(25)}$.

\section{Increasing portion sizes, low prices and increased availability and marketing contribute to the increased consumption of sweetened beverages}

Soda and sweetened fruit drinks are among the least expensive sources of energy ${ }^{(37,38)}$. Although the consumer price index for food rose from 100 in the early 1980 s to 180 by 2002, the price index for fruit and vegetables increased to 258 , whereas that for soda only increased to $126^{(38)}$. Several studies have shown that price reductions and subsidies influence consumer food and

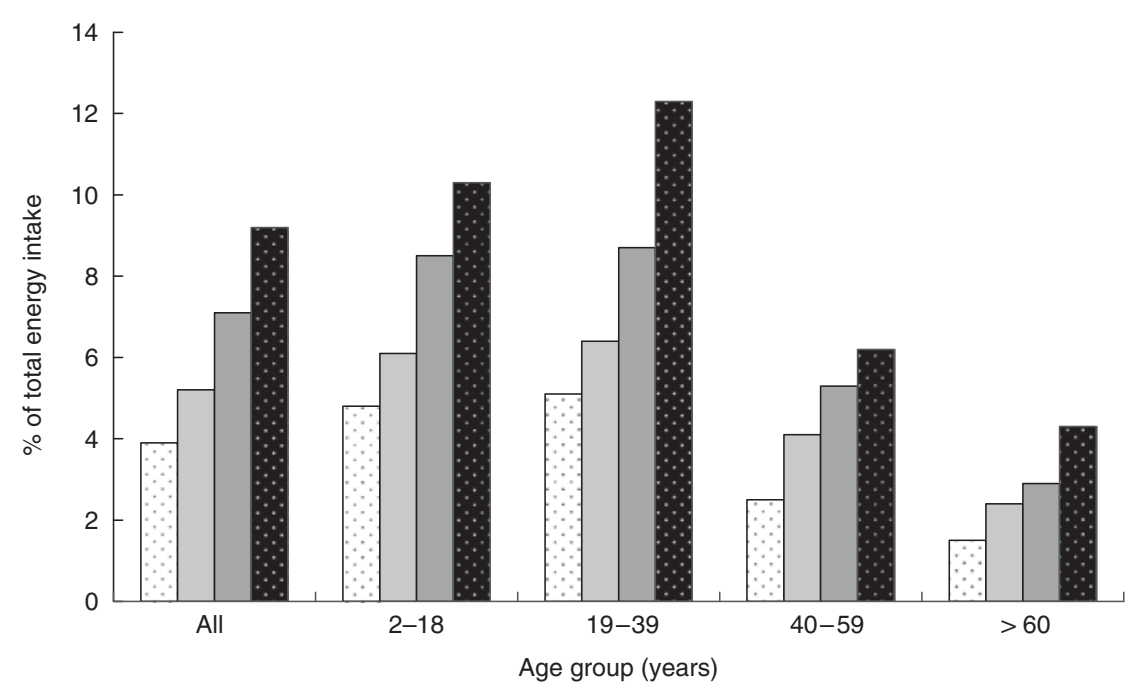

Fig. 2 Trends in US sweetened beverage consumption by age as a percentage of total daily energy intake ( Nationwide Food Consumption Survey, 1977-1978; Continuing Survey of Food Intakes by Individuals, $\square$ 1989-1991, $\square$ 1994-1996; 1 National Health and Nutrition Examination Survey 1999-2001) ${ }^{(24)}$ 
beverage purchases ${ }^{(39-44)}$. The lower-cost beverages are also most consistently associated with weight gain ${ }^{(37)}$.

Sweetened beverage portion sizes have grown from an average serving size of $192 \mathrm{ml} / 368 \mathrm{~kJ}(6.5 \mathrm{fl} \mathrm{oz} / 88 \mathrm{kcal})$ in the $1950 \mathrm{~s}$, to $355 \mathrm{ml} / 669 \mathrm{~kJ}(12 \mathrm{fl} \mathrm{oz} / 160 \mathrm{kcal})$ and $591 \mathrm{ml} /$ $1113 \mathrm{~kJ}$ (20 fl oz/266 kcal) today ${ }^{(26,45)}$. Between 1977 and 1996, the average soda portion size nearly doubled, from $384 \mathrm{ml}(13 \mathrm{fl} \mathrm{oz})$ to nearly $591 \mathrm{ml}(20 \mathrm{fl} \mathrm{oz})^{(45)}$.

Sweetened beverages are heavily promoted on television, websites, games and product placement agreements. In 2000, for example, the soft drink industry spent over \$US700 million on advertising alone, up from \$US381 million in $1986^{(26,46,47)}$. The industry's continued willingness to invest heavily in marketing suggests its efficacy in encouraging consumer purchases.

\section{Mechanisms explaining the relationship between sweetened beverage intake and excess weight gain}

\section{Energy in liquid form is not well regulated and therefore may lead to weight gain}

Research suggests that individuals do not self-regulate energy from beverages as well as energy from solid foods. Mattes $^{(48)}$ estimated from a meta-analysis of over forty studies that, on average, $64 \%$ of food energy from solid foods is offset by subsequent downward adjustment in energy consumed, while only $9 \%$ of liquid energy is compensated for by changes in energy intake. Poor compensation for energy provided in liquid form has been documented by testing a variety of beverages with carbohydrate, fat, protein or energy density of the solids and liquids matched. Clear liquid sources of energy appear to have a lower satiety value than more viscous fluids ${ }^{(49)}$. In addition, adding sweetened drinks to adults' diets has been shown to result in increased self-selected daily energy consumption ${ }^{(47-54)}$. In both short-term and longer-term trials, individuals appear to adjust their intakes of other foods only modestly to compensate for energy consumed in liquid form.

Several mechanisms responsible for this incomplete compensation for liquid sources of energy have been proposed $^{(48,51)}$. As they are typically quickly consumed and rapidly absorbed by the gastrointestinal tract, beverages may not stimulate satiety signals to the same extent as solids. Furthermore, fluids may not be as effective in stimulating insulin release, one of the physiological signals for energy balance ${ }^{(55)}$.

\section{Sweetened beverage intake is consistently associated with bigher energy intake}

Higher consumption of sweetened beverages is consistently associated with higher total energy consumption $^{(21,23,56,57)}$. Adolescents drinking an average of $236 \mathrm{ml}$ ( $8 \mathrm{fl} \mathrm{oz}$ ) or more of soda (non-diet) consumed almost $837 \mathrm{~kJ}(200 \mathrm{kcal})$ more total energy every day than those drinking other types of beverages ${ }^{(21)}$. Children who consumed the largest amounts of sweetened drinks took in $1381 \mathrm{~kJ}$ (330 kcal) more daily energy than did children with the lowest intake ${ }^{(57)}$. In a comparison of intakes measured on two non-consecutive days, children and adolescents' total energy intake was $444 \mathrm{~kJ}$ (106 kcal) higher for each additional serving $(236 \mathrm{ml}(8 \mathrm{fl} \mathrm{oz})$ ) of sugar-sweetened beverage consumed. Wang et al. ${ }^{(58)}$ estimated that total energy intake would be reduced on average by $984 \mathrm{~kJ}(235 \mathrm{kcal}) / \mathrm{d}$ if all sugar-sweetened beverages consumed by 2-19-year-olds were replaced with water. Finally, a recent meta-analysis found that all but two of twenty-one studies (cross-sectional, longitudinal and experimental) showed increased daily energy consumption associated with increased sweetened beverage intake ${ }^{(23)}$. These increases in energy intake without an increase in energy expenditure will inevitably result in weight gain.

\section{Observational studies examining the relationship between sweetened beverage intake and adiposity}

\section{Numerous well-designed observational studies bave found positive associations between sweetened beverage intake and obesity or adiposity}

Fifty-six observational studies were identified that examined the association between sweetened beverage intake and adiposity $^{(2,31,59-109)_{*}}$. Twenty-four were longitudinal ${ }^{(59-82)}$ (i.e. following the same group of people over time to see whether those with higher sweetened beverage intake gained more weight). Sixteen ${ }^{(59,61,62,64,66-68,70-72,74-76,78,81,82)}$ of the longitudinal studies reported a statistically significant positive association and eight reported no significant association between one or more categories of sweetened beverage intake and a measure of adiposity. Twelve of the sixteen longitudinal studies ${ }^{(59,62,64,66-68,70-72,75,76,81,82)}$ that found a positive association received the highest quality 'plus' rating, compared to only three of the eight studies that did not detect a significant association. Therefore, 67\% of the total and $75 \%$ of the highest-quality studies reported a significantly positive association between sweetened beverage intake and adiposity.

Thirty-two cross-sectional analyses examined the association between sweetened beverage intake and adiposity at one point in time $(2,31,59,67,75,83-109)$. Eight were crosssectional studies that included subjects from nationally representative US samples ${ }^{(2,83-89)}$. Three of the six nationally representative studies of children found statistically significant positive associations between sweetened beverage

\footnotetext{
* Adiposity outcome variables were defined in different ways in these studies. Some studies conducted several analyses using different outcome variables. BMI was most commonly used as either a continuous or categorical variable. DXA, BIA or skinfold measures were used in some studies.
} 
intake and adiposity ${ }^{(2,83,86)}$. All three received the highest quality rating, whereas only one of the three that did not find a significant association received the highest quality rating. Two of the studies that did not detect a significant association were conducted by the same author and were funded by the beverage industry ${ }^{(84,85)}$. Therefore, half of the total and $75 \%$ of the highest-quality nationally representative cross-sectional studies in children found a statistically significant positive association between sweetened beverage intake and adiposity.

Only two of the nationally representative studies included adults ${ }^{(88,89)}$. Both received a neutral quality rating; one found a significant positive association between sweetened beverage intake and adiposity ${ }^{(88)}$.

Seventeen of the other (not US nationally representative) observational studies examined the cross-sectional relationship between some type of sweetened beverage intake and adiposity among children ${ }^{(31,59,67,75,90-102)}$. Twelve reported a statistically significant positive association between sweetened beverage intake and some measure of adiposity ${ }^{(31,59,67,75,91-93,95,97-100,102)}$; four found no significant association ${ }^{(90,94,96,101)}$; and one found a significant negative association ${ }^{(99)}$. Seven of the studies that reported a significant positive association and two of those that reported no significant association received the highest (plus) quality rating. The study that reported a negative association received a neutral quality rating. Thus, $63 \%$ of the total studies and $83 \%$ of the highest-quality studies with cross-sectional analyses of children found a significant positive association between sweetened beverage consumption and adiposity.

Seven (not US nationally representative) studies with cross-sectional analyses included adults ${ }^{(103-109)}$. Six reported positive associations ${ }^{(103-107,109)}$ and one reported no statistically significant association ${ }^{(108)}$ between sweetened beverage intake and adiposity. Four of the six studies that found a positive association and the one study that reported no significant association received the highest quality rating ${ }^{(104,105,107,109)}$. Therefore, $86 \%$ of the total and $80 \%$ of the highest-quality studies with cross-sectional analyses of adults reported a statistically significant positive association between sweetened beverage intake and adiposity.

In sum, the majority of longitudinal studies, half of the US nationally representative cross-sectional studies and the majority of other studies with cross-sectional analyses reported a statistically significant association between some type of sweetened beverage intake and adiposity. Of those studies that received the highest quality 'plus' rating, from $75 \%$ to $80 \%$ (depending on the type of study) reported such an association. Only one of the observational studies found a significant negative association between adiposity and any type of sweetened beverage intake and most of the non-significant associations trended in the positive direction.
Intervention trials examining the impact of changes in sweetened beverage intake on body weight

\section{Findings from studies of interventions to reduce sweetened beverage intake suggest a causal association between sweetened beverage intake and weight gain}

Five intervention trials were identified that evaluated the relationship between sweetened beverage consumption and body weight in children aged 6-18 years ${ }^{(110-114)}$. All were successful in reducing sweetened beverage intake compared with control groups. The two studies with stronger designs ${ }^{(111,112)}$ found statistically significant reductions in adiposity or BMI among subjects compared with controls, whereas two studies of weaker (nonrandomized) design found that the observed trends towards lower adiposity were not significant ${ }^{(110,114)}$. A third study of weaker design found that BMI Z-scores increased significantly in the comparison group, but not in the intervention group ${ }^{(113)}$.

Two multi-component studies, the Zuni Diabetes Prevention Program ${ }^{(114)}$ and the Girls' Health Enrichment Multi-site Study (GEMS) ${ }^{(110)}$, included beverage consumption as just one of several intervention components. Neither found a statistically significant relationship between their intervention and BMI change, but neither examined the independent effect of change in sweetened beverage consumption. Furthermore, the Zuni study lacked a true control group and limitations in the sample size and length of the GEMS intervention may have contributed to its lack of significant findings. The absence of significant findings from these two studies is thus neither surprising nor definitive.

Two of the three studies that found significant decreases in body weight from reductions in sweetened beverage consumption were stronger in design. Both were randomized controlled trials examining the independent effect of reducing sweetened beverage intake and were powered to detect changes in physical measures. One, a homebased intervention of 13-18-year-olds, involved counselling and weekly deliveries of non-caloric beverages ${ }^{(111)}$. Subjects experienced lower increases in BMI relative to controls, but this difference was not significant. There was, however, a statistically significant reduction in BMI among the heaviest subjects (upper tertile of baseline BMI), who reduced their BMI by 0.63 points, while the control group increased their BMI by $0 \cdot 12$ points.

The Christchurch Obesity Prevention Project in Schools focused exclusively on discouraging the consumption of carbonated beverages ${ }^{(112)}$. Four educational sessions were delivered over a 1-year period to students aged 7-11 years. Findings showed a statistically significant reduction in the percentage of children who stayed overweight in the intervention group as compared to an increase in the percentage of children who became overweight in the control group. 
The third study, an evaluation of a naturalistic experiment, that reported a significant impact on BMI was weaker in design ${ }^{(113)}$. It compared students at elementary schools that had $v$. had not adopted policies providing nutritious food choices and physical activity. The schools were not randomly assigned to these groups. Although this was a multi-component study, the only dietary variable that changed significantly in the intervention group was sweetened beverage intake; physical activity did not appear to change.

\section{Findings from experimental studies designed to increase sweetened beverage intake also suggest a causal relationship between sweetened beverage intake and weight gain}

In one cross-over study, thirty normal-weight adults were given artificially sweetened soda, soda sweetened with high-fructose corn syrup or no soda supplementation over successive 3 -week periods ${ }^{(50)}$. The regular soda provided the equivalent of four to five $330 \mathrm{ml}(3-412 \mathrm{fl} \mathrm{oz})$ cans each day. Participants were not told which type of soda they were given. When consuming regular soda, participants increased their energy intake by $13 \%$ and gained an average of $0.7 \mathrm{~kg}(1.04 \mathrm{lbs})$, gains that were significant compared with the other conditions. Another cross-over trial tested the adjustments in intake over 4-week periods of supplementation with $1879 \mathrm{~kJ}(450 \mathrm{kcal}) / \mathrm{d}$ in either a solid (jelly beans) or liquid (soda) form ${ }^{(51)}$. Weight significantly increased when energy was provided in liquid compared with solid form. Compensation for the additional energy provided as a liquid averaged only $17 \%$.

A randomized controlled trial of forty-one overweight adults followed for 10 weeks provided either sucrose $(3347 \mathrm{~kJ}(800 \mathrm{kcal}) / \mathrm{d})$ or artificial sweeteners primarily in the form of soft drinks and fruit drinks ${ }^{(52)}$. The sucrose group increased its total energy intake by $1615 \mathrm{~kJ}(386 \mathrm{kcal}) / \mathrm{d}$ and gained $1.6 \mathrm{~kg}(3.5 \mathrm{lbs})$, whereas those given diet beverages decreased their total energy intake by $439 \mathrm{~kJ}(105 \mathrm{kcal}) / \mathrm{d}$ and lost $1 \mathrm{~kg}(2 \cdot 2 \mathrm{lbs})$ - a significant difference between the groups of over $0 \cdot 2 \mathrm{~kg}(0 \cdot 5 \mathrm{lb}) /$ week. In a 4 -week trial of 133 women involving sucrose $v$. artificially sweetened beverages, those provided $1799 \mathrm{~kJ}(430 \mathrm{kcal}) / \mathrm{d}$ in the form of sucrose-sweetened drinks consumed an extra $795 \mathrm{~kJ}$ (190 kcal) total daily ${ }^{(54)}$. In both of these studies, the subjects decreased their usual intake by an amount equal to only half of the liquid energy they were given.

In summary, all four experimental studies found that increases in sweetened beverage intake resulted in significant increases in both energy intake and weight.

\section{Meta-analyses that determined effect size}

Two meta-analyses were identified that examine the magnitude of the effect of sweetened beverages on body weight. Combining thirty-three cross-sectional, longitudinal observational and intervention studies of adults and children, Vartanian et $a l .{ }^{(115)}$ used a standardized measure to calculate a statistically significant effect size equivalent to a $0 \cdot 08 \mathrm{SD}$ change in BMI for each SD change in energy from sweetened beverages. Larger effect sizes were observed for intervention trials, studies involving adults, studies focusing on soft drinks and studies not funded by the beverage industry. Based on the calculated associations of sweetened beverage intake with increased energy intake, decreased intake of milk, calcium and other nutrients, increased body weight and health problems such as type 2 diabetes, the authors concluded that recommendations to reduce soft drink consumption were clearly supported by science.

Forshee et $a .^{(116)}$ analysed ten longitudinal and intervention studies of children and adolescents. The maximum estimated effect size of 0.02 units of BMI change for each daily serving change in sweetened beverage consumption was not significantly different from zero. Given the variable length of the studies, it is not possible to translate this effect size into anticipated weight gain. The authors conclude that reducing the consumption of sweetened beverages would not have a measurable impact on BMI among youth. Of note, this meta-analysis was conducted by authors who received funding from the American Beverage Association.

A letter to the editor written by Malik et $a l^{(117)}$ criticized this meta-analysis for failing to weight studies appropriately and failing to exclude studies of weaker design. Both authors conducted the analysis again; Forshee et $a l^{(118)}$ only corrected the weighting error, whereas Malik et al. corrected for all the weaknesses they had identified. Forshee's revised analysis produced an effect size of 0.03 unit change in BMI per $355 \mathrm{ml}(12 \mathrm{floz})$ of soda/d over the study time period (which varied); Malik et al. ${ }^{(119)}$ reported a statistically significant effect size of 0.08 unit change in BMI per $355 \mathrm{ml}$ (12 fl oz) of soda.

\section{Contribution of sweetened beverages to increases in energy consumption in the USA}

According to data from national surveys of dietary intake among individuals 2 years old and above, per capita energy intake increased from $7489 \mathrm{~kJ}(1790 \mathrm{kcal}) / \mathrm{d}$ in $1977-1978$ to $11213 \mathrm{~kJ}(2068 \mathrm{kcal}) / \mathrm{d}$ in $1999-2001^{(24)}$, an increase of $1163 \mathrm{~kJ}$ ( $278 \mathrm{kcal}) / \mathrm{d}$ (Table 1). Over the same time period, per capita energy from sweetened beverages increased from 293 to $795 \mathrm{~kJ}(70-190 \mathrm{kcal}) / \mathrm{d}$, an increase of $502 \mathrm{~kJ}(120 \mathrm{kcal}) / \mathrm{d}$. Therefore, the increase in these sweetened beverages is equivalent to $43 \%$ of the increase in energy consumption.

Given that physical activity levels have not increased substantially in recent decades ${ }^{(6-10)}$, the increase in per capita energy intake during this period was likely to have been in excess of average energy needs and therefore to have contributed to excess weight gain in the US population. Although some of the increase in energy from sweetened 
Table 1 Proportion of increase in total energy intake from sweetened beverages, 1977-2001

\begin{tabular}{|c|c|c|c|c|}
\hline & $1977-1978$ & 1999-2001 & Unadjusted difference & $\begin{array}{l}\text { Difference adjusted for } \\
\text { compensatory intake }\end{array}$ \\
\hline $\begin{array}{l}\text { Total } \mathrm{kJ}(\mathrm{kcal}) / \mathrm{d} \text { per capita } \\
\mathrm{kJ}(\mathrm{kcal}) / \mathrm{d} \text { per capita from sweetened beverages } \\
\text { Percentage of increase in total energy intake from } \\
\text { sweetened beverages }\end{array}$ & $\begin{array}{l}7489(1790) \\
293(70)\end{array}$ & $\begin{array}{c}8653(2068) \\
795(190)\end{array}$ & $\begin{array}{c}1164(278) \\
501(120) \\
43\end{array}$ & $\begin{array}{c}N / A \\
251(60) \\
22\end{array}$ \\
\hline
\end{tabular}

N/A, not applicable.

Sources: Nationwide Food Consumption Survey, 1977-1978; National Health and Nutrition Examination Survey, 1999-2001 (24).

beverages may have been compensated for by a decrease in other foods or beverages, the available evidence suggests that this compensation is incomplete and is unlikely to be higher than $50 \%{ }^{(48,50-52,54)}$. Even if compensation as high as $50 \%$ did occur, sweetened beverages would still have accounted for close to one-fifth of the net weight gained in the USA between 1977-1978 and 1999-2001, when obesity rates were increasing most rapidly.

\section{Discussion and conclusion}

All five categories of evidence examined (secular trends, mechanisms, observational studies, intervention trials and meta-analyses) provide support for the hypothesis that the intake of sweetened beverages increases the risk of overweight. The population-wide increase in the intake of sweetened beverages in the USA corresponds with increases in energy intake and obesity. Studies show that energy intake from sugar in liquid form is not well compensated for by reductions in subsequent intake and that sweetened beverage intake is consistently associated with higher energy intake.

The majority of observational studies, including the more conclusive longitudinal studies, and those of more rigorous design and higher quality in every category (cross-sectional, longitudinal, nationally representative, adults and children) show that sweetened beverage intake is significantly associated with greater adiposity. Only one study reported a significant negative association between any type of sweetened beverage intake and adiposity among any age or ethnic group.

Most importantly, two randomized controlled trials showed that successful reduction of sweetened beverage intake resulted in reductions in adiposity among children. Similarly, four trials to increase intake of sweetened beverages consistently showed weight gain among freeliving adults. Two additional trials that failed to detect a significant impact on adiposity were less appropriately designed to address this hypothesis.

Although the two meta-analyses examined initially arrived at different conclusions, the more comprehensive and rigorous analysis did report a significant effect size. A re-analysis by another group of the second study (which initially yielded insignificant results) addressed several methodological issues and produced significant results similar in magnitude to the first. Furthermore, a simple analysis of national (US) dietary intake data found that the increase in sweetened beverage intake accounted for $43 \%$ of the per capita increase in total energy intake and therefore most likely contributed to at least one-fifth of the weight gained over the time period when obesity rates were increasing most rapidly.

While more studies are warranted - particularly longterm, randomized controlled trials - the currently available evidence is extensive and consistently supports the hypothesis that sweetened beverage intake is a risk factor for the development of obesity and has made a substantive contribution to the obesity epidemic experienced in the USA in recent decades.

Sweetened beverages are an especially promising focus for efforts to prevent and reduce obesity for two reasons: (i) the evidence supporting the association between sweetened beverage intake and excess weight is stronger than for any other single type of food or beverage ${ }^{(20)}$; and (ii) sweetened beverages provide no nutritional benefit other than energy and water. One simple dietary change - reducing the consumption of sweetened sodas could have a measurable impact on obesity without any negative dietary consequences.

Although educational efforts to reduce sweetened beverage intake are an important element of any strategy to reduce intake ${ }^{(111,112)}$, it is well recognized that the increases in obesity in recent decades are most likely the result of environmental and policy influences ${ }^{(120,121)}$. Given that increasing portion sizes, low prices and increased availability and marketing have most likely contributed to the increased consumption of sweetened beverages ${ }^{(26,37-47)}$, efforts to reduce sweetened beverage intake would be well advised to focus on these factors.

\section{Acknowledgements}

The present publication was made possible with funding from The California Endowment, the California Center for Public Health Advocacy and the Centers for Disease Control and Prevention, Cooperative Agreement U48/ CCU909706-10. All authors are employees of a public, non-profit university. All authors contributed to the 
drafting of this paper and approved the final version. G.W.L. and L.R. participated in the literature review process, synthesized/interpreted the compiled information and drafted the paper; J.K. supervised the literature review process, reviewed and provided feedback on the written paper. The authors wish to acknowledge the contribution of Sarah Kim, who abstracted and rated the observational studies referred to in this report; and Sheila Stern MA, and Peg Farrell, MA, who reviewed and edited the final version. The authors also gratefully acknowledge the following national panel of experts for their review and input of this analysis: George Bray, MD, Boyd Professor, Pennington Center, Louisiana State University; Steven Hooker, PhD, Director, Prevention Research Center, University of South Carolina; Richard Mattes, MPH, PhD, RD, Professor, Foods and Nutrition, Purdue University; Barry Popkin, PhD, Professor, Department of Nutrition, Gillings School of Public Health, and Director, Interdisciplinary Obesity Center, University of North Carolina; Jim Sallis, PhD, Professor, Department of Psychology, San Diego State University, and Program Director, Active Living Research, The Robert Wood Johnson Foundation; Marlene Schwartz, PhD, Deputy Director, Rudd Center for Food Policy and Obesity, Yale University; Mary Story, PhD, Professor, Division of Epidemiology, School of Public Health, University of Minnesota, and Director, Healthy Eating Research, The Robert Wood Johnson Foundation; Y. Claire Yang, MD, Assistant Professor of Health Policy \& Management, Mailman School of Public Health, Columbia University.

\section{References}

1. Bates LM, Acevedo-Garcia D, Alegria M et al. (2008) Immigration and generational trends in body mass index and obesity in the United States: results of the National Latino and Asian American Survey, 2002-2003. Am J Public Health 98, 70-77.

2. Troiano RP, Briefel RR, Carroll MD et al. (2000) Energy and fat intakes of children and adolescents in the United States: data from the National Health and Nutrition Examination Surveys. Am J Clin Nutr 72, 5 Suppl., S1343-S1353.

3. Bleich SN, Cutler D, Murray C et al. (2008) Why is the developed world obese? Annu Rev Public Health 29, 273-295.

4. US Department of Agriculture, Economic Research Service (2003) Food consumption per capita data system. http:// www.ers.usda.gov/data/food-consumption/DataSystem.asp? $\mathrm{ERSTab}=3$ (accessed May 2003).

5. Nielsen SJ, Siega-Riz AM \& Popkin BM (2002) Trends in food locations and sources among adolescents and young adults. Prev Med 35, 107-113.

6. California Department of Health Services (2000) Nutrition and Physical Activity Guidelines for Adolescents. http:// www.cdph.ca.gov/HealthInfo/healthyliving/childfamily/ Documents/MO-NutritionandPhysicalActivityGuidelines.pdf (accessed October 2009).

7. Brownson RC, Boehmer TK \& Luke DA (2005) Declining rates of physical activity in the United States: what are the contributors? Annu Rev Public Health 26, 421-443.
8. Kruger J, Kohl HW III \& Miles IJ (2007) Prevalence of regular physical activity among adults - United States, 2001 and 2005. MMWR 56, 1209-1212.

9. Stanford Prevention Research Center (2007) Building 'Generation Play': addressing the crisis of inactivity among America's children. http://www.playeveryday.org/Stanford Report.pdf (accessed June 2008).

10. Westerterp KR \& Speakman JR (2008) Physical activity energy expenditure has not declined since the 1980s and matches energy expenditures of wild mammals. Int $J$ Obes 32, 1256-1263.

11. Centers for Disease Control and Prevention (2008) Prevalence of self-reported physically active adults United States, 2007. MMWR 57, 1297-1300.

12. Troiano RP, Berrigan D, Dodd KW et al. (2008) Physical activity in the United States measured by accelerometer. Med Sci Sports Exerc 40, 181-188.

13. Matthews CE, Chen KY, Freedson PS et al. (2008) Amount of time spent in sedentary behaviors in the United States, 2003-2004. Am J Epidemiol 167, 875-881.

14. Prentice A \& Jebb S (2004) Energy intake/physical activity interactions in the homeostasis of body weight regulation. Nutr Rev 62, S98-S104.

15. Gerstein D, Woodward-Lopez G, Evans A et al. (2004) Clarifying concepts about macronutrients' effects on satiation and satiety. J Am Diet Assoc 104, 1151-1153.

16. Muñoz KA, Krebs-Smith SM et al. (1997) Food intakes of US children and adolescents compared with recommendations. Pediatrics 100, part 1, 323-329.

17. Bachman JL, Reedy J, Subar AF et al. (2008) Sources of food group intakes among the US population, 2001-2002. $J$ Am Diet Assoc 108, 804-814.

18. Johnson RK \& Frary C (2001) Choose beverages and foods to moderate your intake of sugars: the 2000 Dietary Guidelines for Americans - what's all the fuss about? J Nutr 131, S2766-S2771.

19. Guthrie JF \& Morton JF (2000) Food sources of added sweeteners in the diets of Americans. J Am Diet Assoc 100, 43-51.

20. Woodward-Lopez G, Ritchie L, Gerstein D et al. (2006) Obesity: Dietary and Developmental Influences. Boca Raton, FL: CRC Press.

21. Harnack L, Stang J \& Story M (1999) Soft drink consumption among US children and adolescents: nutritional consequences. J Am Diet Assoc 99, 436-441.

22. Guthrie JF (1996) Dietary patterns and personal characteristics of women consuming recommended amounts of calcium. Fam Econ Nutr Rev 9, 33-49.

23. Vartanian LR, Schwartz MB \& Brownell KD (2007) Effects of soft drink consumption on nutrition and health: a systematic review and meta-analysis. Am J Public Health 97, 667-675.

24. Nielsen SJ \& Popkin BM (2004) Changes in beverage intake between 1977 and 2001. Am J Prev Med 27, 205-210.

25. Bleich SN, Wang CY, Wang Y et al. (2009) Increasing consumption of sugar-sweetened beverages among US adults: 1988-1994 to 1999-2004. Am J Clin Nutr 89, 372-381.

26. Jacobson MF (2005) Liquid candy: how soft drinks are harming Americans' health. http://www.cspinet.org/liquidcandy/ (accessed June 2008).

27. Skinner JD \& Carruth BR (2001) A longitudinal study of children's juice intake and growth: the juice controversy revisited. J Am Diet Assoc 101, 432-437.

28. West S, King V, Carey TS et al. (2002) Systems to rate the strength of scientific evidence. Evid Rep Technol Assess (Summ) 47, 1-11.

29. Duffey KJ \& Popkin BM (2007) Shifts in patterns and consumption of beverages between 1965 and 2002 . Obesity 15, 2739-2747. 
30. Wang YC, Bleich SN \& Gortmaker SL (2008) Increasing caloric contribution from sugar-sweetened beverages and $100 \%$ fruit juices among US children and adolescents, 1988-2004. Pediatrics 121, E1604-E1614.

31. Giammattei J, Blix G, Marshak HH et al. (2003) Television watching and soft drink consumption: associations with obesity in 11- to 13-year-old schoolchildren. Arch Pediatr Adolesc Med 157, 882-886.

32. Miech RA, Kumanyika SK, Stettler N et al. (2006) Trends in the association of poverty with overweight among US adolescents 1971-2004. JAMA 295, 2385-2393.

33. Fox MK, Pac S, Devaney B et al. (2004) Feeding Infants and Toddlers Study: what foods are infants and toddlers eating? J Am Diet Assoc 104, S31-S37.

34. United States Department of Agriculture, Agricultural Research Service (1997) Data tables: results from USDA's 1994-96 Continuing Survey of Food Intakes by Individuals and 1994-96 Diet and Health Knowledge Survey. http://www.barc.usda.gov/bhnrc/foodsurvey/pdf/Csfii3yr. pdf

35. Block G (2004) Foods contributing to energy intake in the US: data from NHANES III and NHANES 1999-2000. J Food Compost Anal 17, 439-447.

36. Lytle LA, Seifert S, Greenstein J et al. (2000) How do children's eating patterns and food choices change over time? Results from a cohort study. Am J Health Promot $\mathbf{1 4}$, 222-228.

37. Drewnowski A \& Bellisle F (2007) Liquid calories, sugar, and body weight. Am J Clin Nutr 85, 651-661.

38. Sturm R (2005) Childhood obesity: what we can learn from existing data on societal trends: Part 2. Prev Chronic Dis 2, A20.

39. French SA, Story M, Jeffery RW et al. (1997) Pricing strategy to promote fruit and vegetable purchase in high school cafeterias. J Am Diet Assoc 97, 1008-1010.

40. French SA (2003) Pricing effects on food choices. J Nutr 133, 841S-843S.

41. French SA (2005) Public health strategies for dietary change: schools and workplaces. J Nutr 135, 910-912.

42. Anderson JV, Bybee DI, Brown RM et al. (2001) 5-a-day fruit and vegetable intervention improves consumption in a low income population. J Am Diet Assoc 101, 195-202.

43. Herman D (2008) Low-income women purchase a variety of fruits and vegetables when provided with an economic incentive. FASEB J 19, Suppl. 5, A1697.

44. Johnson DB, Beaudoin S, Smith LT et al. (2004) Increasing fruit and vegetable intake in homebound elders: the Seattle Senior Farmers' Market Nutrition Pilot Program. Prev Chronic Dis 1, A03.

45. Nielsen SJ \& Popkin BM (2003) Patterns and trends in food portion sizes, 1977-1998. JAMA 289, 450-453.

46. Beverage Digest (1998) Fact Book 1998, pp. 54-55. Bedford Hill, NY: Beverage Digest.

47. Gallo AE (1999) Food advertising in the United States. In America's Eating Habits: Changes and Consequences Agriculture Information Bulletin no. (AIB750), pp. 173-180 [E Frazao, editor]. Washington, DC: USDA.

48. Mattes RD (1996) Dietary compensation by humans for supplemental energy provided as ethanol or carbohydrate in fluids. Physiol Behav 59, 179-187.

49. Mattes R (2006) Fluid calories and energy balance: the good, the bad, and the uncertain. Physiol Behav 89, $66-70$.

50. Tordoff MG \& Alleva AM (1990) Effect of drinking soda sweetened with aspartame or high-fructose corn syrup on food intake and body weight. Am J Clin Nutr $\mathbf{5 1}$, 963-969.

51. DiMeglio DP \& Mattes RD (2000) Liquid versus solid carbohydrate: effects on food intake and body weight. Int J Obes 24, 794-800.
52. Raben A, Vasilaras TH, Møller AC et al. (2002) Sucrose compared with artificial sweeteners: different effects on ad libitum food intake and body weight after $10 \mathrm{wk}$ of supplementation in overweight subjects. Am J Clin Nutr 76, 721-729.

53. Van Wymelbeke V, Béridot-Thérond ME, de La Guéronnière V et al. (2004) Influence of repeated consumption of beverages containing sucrose or intense sweeteners on food intake. Eur J Clin Nutr 58, 154-161.

54. Reid M, Hammersley R, Hill AJ et al. (2007) Long-term dietary compensation for added sugar: effects of supplementary sucrose drinks over a 4-week period. Br J Nutr 97, 193-203.

55. Teff K (1994) Cephalic phase insulin release in humans: mechanism and function. In Appetite and Body Weight Regulation: Sugar, Fat, and Macronutrient Substitutes, pp. 37-50 [JD Fernstrom and GD Miller, editors]. Boca Raton, FL: CFC Press Inc.

56. Guenther PM (1986) Beverages in the diets of American teenagers. J Am Diet Assoc 86, 493-499.

57. Cullen KW, Ash DM, Warneke C et al. (2002) Intake of soft drinks, fruit-flavored beverages, and fruits and vegetables by children in grades 4 through 6. Am J Public Health 92 , 1475-1477.

58. Wang YC, Ludwig DS, Sonneville K et al. (2009) Impact of change in sweetened caloric beverage consumption on energy intake among children and adolescents. Arch Pediatr Adolesc Med 163, 336-343.

59. Berkey CS, Rockett HRH, Field AE et al. (2004) Sugaradded beverages and adolescent weight change. Obes Res 12, 778-788.

60. Blum JW, Jacobsen DJ \& Donnelly JE (2005) Beverage consumption patterns in elementary school aged children across a two-year period. J Am Coll Nutr 24, 93-98.

61. Dubois L, Farmer A, Girard M et al. (2007) Regular sugarsweetened beverage consumption between meals increases risk of overweight among preschool-aged children. J Am Diet Assoc 107, 924-934.

62. Fiorito LM, Marini M, Francis LA et al. (2009) Beverage intake of girls at age 5 y predicts adiposity and weight status in childhood and adolescence. Am J Clin Nutr $\mathbf{9 0}$, 935-942.

63. Johnson L, Mander AP, Jones LR et al. (2007) Is sugarsweetened beverage consumption associated with increased fatness in children? Nutrition 23, 557-563.

64. Kral TVE, Stunkard AJ, Berkowitz RI et al. (2008) Beverage consumption patterns of children born at different risk of obesity. Obesity 16, 1802-1808.

65. Laurson K, Eisenmann JC \& Moore S (2008) Lack of association between television viewing, soft drinks, physical activity, and body mass index in children. Acta Paediatr 97, 795-800.

66. Libuda L, Alexy U, Sichert-Hellert W et al. (2008) Pattern of beverage consumption and long-term association with body-weight status in German adolescents - results from the DONALD study. Br J Nutr 99, 1370-1379.

67. Lim S, Zoellner JM, Lee JM et al. (2009) Obesity and sugar-sweetened beverages in African-American preschool children: a longitudinal study. Obesity 17, 1262-1268.

68. Ludwig DS, Peterson KE \& Gortmaker SL (2001) Relation between consumption of sugar-sweetened drinks and childhood obesity. Lancet 357, 505-508.

69. Newby PK, Peterson KE, Berkey CS et al. (2004) Beverage consumption is not associated with changes in weight and body mass index among low-income preschool children in North Dakota. J Am Diet Assoc 104, 1086-1094.

70. Nissinen K, Mikkilä V, Männistö S et al. (2009) Sweets and sugar-sweetened soft drink intake in childhood in relation to adult BMI and overweight. The Cardiovascular Risk in Young Finns Study. Public Health Nutr 12, 2018-2026. 
71. Phillips SM, Bandini LG, Naumova EN et al. (2004) Energydense snack food intake in adolescence: longitudinal relationship to weight and fatness. Obes Res 12, 461-472.

72. Striegel-Moore RH, Thompson D, Affenito SG et al. (2006) Correlates of beverage intake in adolescent girls: The National Heart, Lung, and Blood Institute Growth and Health Study. J Pediatr 148, 183-187.

73. Sugimori H, Yoshida K, Iauno T et al. (2004) Analysis of factors that influence body mass index from ages 3 to 6 years: a study based on the Toyama cohort study. Pediatr Int 46, 302-310.

74. Tam CS, Garnett SP, Cowell CT et al. (2006) Soft drink consumption and excess weight gain in Australian school students: results from the Nepean study. Int J Obes 30, 1091-1093.

75. Warner ML, Harley K, Bradman A et al. (2006) Soda consumption and overweight status of 2-year-old Mexican-American children in California. Obesity 14, 1966-1974.

76. Welsh JA, Cogswell ME, Rogers S et al. (2005) Overweight among low-income preschool children associated with the consumption of sweet drinks: Missouri, 1999-2002. Pediatrics 115, e223-e229.

77. Vanselow MS, Pereira MA, Neumark-Sztainer D et al. (2009) Adolescent beverage habits and changes in weight over time: findings from Project EAT. Am J Clin Nutr 90, 1489-1495.

78. Bes-Rastrollo M, Sanchez-Villegas A, Gomez-Gracia E et al. (2006) Predictors of weight gain in a Mediterranean cohort: the Seguimento Universidad de Navarra Study. Am J Clin Nutr 83, 362-370.

79. French SA, Jeffery RW, Forster JL et al. (1994) Predictors of weight change over two years among a population of working adults: The Healthy Worker Project. Int J Obes 18, 145-154.

80. Kvaavik E, Andersen LF \& Klepp KI (2004) The stability of soft drinks intake from adolescence to adult age and the association between long-term consumption of soft drinks and lifestyle factors and body Weight. Public Health Nutr 8, 149-157.

81. Palmer JR, Boggs DA, Krishnan S et al. (2008) Sugarsweetened beverages and incidence of type 2 diabetes mellitus in African American women. Arch Intern Med 168, 1487-1492.

82. Schulze MB, Manson JE, Ludwig DS et al. (2004) Sugarsweetened beverages, weight gain, and incidence of type 2 diabetes in young and middle-aged women. JAMA $\mathbf{2 9 2}$, 927-934.

83. Bremer AA, Auinger P \& Byrd RS (2009) Relationship between insulin resistance-associated metabolic parameters and anthropometric measurements with sugar-sweetened beverage intake and physical activity levels in US adolescents. Arch Pediatr Adolesc Med 163, 328-335.

84. Forshee RA \& Storey ML (2003) Total beverage consumption and beverage choices among children and adolescents. Int J Food Sci Nutr 54, 297-307.

85. Forshee RA, Anderson PA \& Storey ML (2004) The role of beverage consumption, physical activity, sedentary behavior, and demographics on body mass index of adolescents. Int J Food Sci Nutr 55, 463-478.

86. LaRowe TL, Moeller SM \& Adams AK (2007) Beverage patterns, diet quality, and body mass index of US preschool and school-aged children. J Am Diet Assoc 107, $1124-1133$.

87. O'Connor TM, Yang S \& Nicklas TA (2006) Beverage intake among preschool children and its effect on weight status. Pediatrics 118, e1010-e1018.

88. Lin BH, Huang CL \& French SA (2004) Factors associated with women's and children's body mass indices by income status. Int J Obes Relat Metab Disord 28, 536-542.
89. Sun SZ \& Empie MW (2007) Lack of findings for the association between obesity risk and usual sugar-sweetened beverage consumption in adults - a primary analysis of databases of CSFII 1989-1991, CSFII 1994-1998, NHANES III, and combined NHANES 1999-2002. Food Chem Toxicol 45, 1523-1536.

90. Andersen LF, Lillegaard ITL, Overby N et al. (2005) Overweight and obesity among Norwegian schoolchildren: changes from 1993-2000. Scand J Public Health 33, 99-106.

91. Ariza AJ, Chen EH, Binns HJ et al. (2004) Risk factors for overweight in five- to six-year-old Hispanic American children: a pilot study. J Urban Health 81, 150-161.

92. Gibson S \& Neate D (2007) Sugar intake, soft drink consumption, and body weight among British children: further analysis of National Diet and Nutrition Survey data with adjustment for under-reporting and physical activity. Int J Food Sci Nutr 58, 445-460.

93. Gillis LJ \& Bar-Or O (2003) Food away from home, sugarsweetened drink consumption, and juvenile obesity. J Am Coll Nutr 22, 539-545.

94. Gómez-Martínez S, Martín A, Romeo J et al. (2009) Is soft drink consumption associated with body composition? A cross-sectional study in Spanish adolescents. Nutr Hosp 24, 97-102.

95. Linardakis M, Sarri K, Pateraki M-S et al. (2008) Sugaradded beverages consumption among kindergarten children of Crete: effects on nutritional status and risk of obesity. BMC Public Health 8, 279-285.

96. Mahmood M, Saleh A, Al-Alawi F et al. (2008) Health effects of soda drinking in adolescent girls in the United Arab Emirates. J Crit Care 23, 435-440.

97. Nicklas TA, Yang S, Baranowski T et al. (2003) Eating patterns and obesity in children: The Bogalusa Heart Study. Am J Prev Med 25, 9-16.

98. Ochoa MC, Moreno-Aliaga MJ, Martinez-Gonzalez MA et al. (2007) Predictor factors for childhood obesity in a Spanish case-control study. Nutrition 23, 379-384.

99. Overby NC, Lillegaard ITL, Johansson L et al. (2003) High intake of added sugar among Norwegian children and adolescents. Public Health Nutr 7, 285-293.

100. Rockett HRH, Berkey CS, Field AE et al. (2001) Crosssectional measurement of nutrient intake among adolescents in 1996. Prev Med 33, 27-37.

101. Rodríguez-Artalejo F, García EL, Gorgojo L et al. (2003) On behalf of the investigators of the Four Provinces Study. Consumption of bakery products, sweetened soft drinks and yogurt among children aged 6-7 years: association with nutrient intake and overall diet quality. BrJ Nutr 89, 419-419.

102. Sanigorski AM, Bell AC \& Swinburn BA (2007) Association of key foods and beverages with obesity in Australian schoolchildren. Public Health Nutr 10, 152-157.

103. French SA, Jeffery RW, Forster JL et al. (1994) Predictors of weight change over two years among a population of working adults: the Healthy Worker Project. Int J Obes 18, $145-154$.

104. Kent LM \& Worsley A (2008) Does the prescriptive lifestyle of Seventh-day Adventists provide 'immunity' from the secular effects of changes in BMI? Public Health Nutr 12, 472-480.

105. Leon-Guerrero RT, Paulino YC, Novotny R et al. (2008) Diet and obesity among Chamorro and Filipino adults on Guam. Asia Pac J Clin Nutr 17, 216-222.

106. Liebman M, Pelican S, Moore SA et al. (2003) Dietary intake, eating behavior, and physical activity-related determinants of high body mass index in rural communities in Wyoming, Montana, and Idaho. Int J Obes $\mathbf{2 7}$, 684-692.

107. Novotny R, Williams AE, Vinoya AC et al. (2009) US acculturation, food intake, and obesity among AsianPacific hotel workers. J Am Diet Assoc 109, 1712-1718. 
108. O'Neil CE, Nicklas TA, Liu Y et al. (2009) Impact of dairy and sweetened beverage consumption on diet and weight of a multiethnic population of Head Start mothers. $J$ Am Diet Assoc 109, 874-882.

109. Rehm CD, Matte TD et al. (2008) Demographic and behavioral factors associated with daily sugar-sweetened soda consumption in New York City adults. J Urban Health 85, 375-385.

110. Beech BM, Klesges RC, Kumanyika SK et al. (2003) Childand parent-targeted interventions: the Memphis GEMS pilot study. Ethn Dis 13, S40-S52.

111. Ebbeling CB, Feldman HA, Osganian SK et al. (2006) Effects of decreasing sugar-sweetened beverage consumption on body weight in adolescents: a randomized, controlled pilot study. Pediatrics 117, 673-680.

112. James J, Thomas P, Cavan D et al. (2004) Preventing childhood obesity by reducing consumption of carbonated drinks: cluster randomized controlled trial. BMJ 328, 1237-1242.

113. Jordan KC, Erickson ED, Cox R et al. (2008) Evaluation of the Gold Medal Schools Program. J Am Diet Assoc 108, 1916-1920.

114. Teufel NI \& Ritenbaugh CK (1998) Development of a primary prevention program: insight gained in the
Zuni Diabetes Prevention Program. Clin Pediatr 37, 131-142.

115. Vartanian LR, Schwartz MB \& Brownell KD (2007) Effects of soft drink consumption on nutrition and health: a systematic review and meta-analysis. Am J Public Health 97, 667-675.

116. Forshee RA, Anderson PA \& Storey ML (2008) Sugarsweetened beverages and body mass index in children and adolescents: a meta-analysis. Am J Clin Nutr 87, 1662-1671.

117. Malik VS, Willett WC \& Hu FB (2009) Sugar-sweetened beverages and BMI in children and adolescents: reanalyses of a meta-analysis. Am J Clin Nutr 89, 438-439.

118. Forshee RA, Storey ML \& Anderson PA (2009) Reply to VS Malik et al. Am J Clin Nutr 89, 439-440.

119. Malik VS, Schulze MB \& Hu FB (2006) Intake of sugarsweetened beverages and weight gain: a systematic review. Am J Clin Nutr 84, 274-288.

120. French SA, Story M \& Jeffery RW (2001) Environmental influences on eating and physical activity. Annu Rev Public Health 22, 309-335.

121. Swinburn BA, Caterson I, Seidell JC et al. (2004) Diet, nutrition, and the prevention of excess weight gain and obesity. Public Health Nutr 7, 123-146. 